\title{
Transformasi Digital bagi UMKM dengan Perancangan Enterprise Architecture Menggunakan TOGAF ADM
}

\author{
(Studi Kasus : UMKM Penghasil Makanan Khas Daerah)
}

\author{
Rahmania Arina Alkha Saputri \\ Fakultas Rekayasa Industri, Jurusan Sistem Informasi \\ Universitas Telkom \\ Jalan Telekomunikasi No.1, Bandung \\ rahmaniaaas@student.telkomuniversity.ac.id
}

\author{
Asti Amalia Nur Fajrillah \\ Fakultas Rekayasa Industri, Jurusan Sistem Informasi \\ Universitas Telkom \\ Jalan Telekomunikasi No.1, Bandung \\ astiamalia@telkomuniversity.ac.id
}

\begin{abstract}
Abstrak - Dewasa ini, UMKM di hampir semua industri telah melakukan inisiatif untuk bertransformasi memanfaatkan teknologi. Adanya tranformasi digital yang berbasis sistem informasi, nilai bisnis diyakini akan semakin meningkat. Namun demikian, bisnis UMKM tidak selalu berjalan mulus dengan penerapan transformasi digital. Masih banyaknya hambatan dan kendala yang harus dihadapi UMKM. Beberapa kendala yang dialami oleh UMKM Penghasil Makanan Khas Daerah antara lain seperti keterbatasan mendapatkan pasokan bahan baku, banyaknya pesaing produk yang sama, catatan keuangan yang masih manual, belum adanya standarisasi produk, jangkauan pemasaran yang masih sempit, dan keterbatasan inovasi pengolahan kacang. Maka dari itu, perlunya pemanfaatan teknologi informasi pengelolaan operasional yang selaras dengan kebutuhan bisnis UMKM. Penyelarasan antara bisnis dan teknologi UMKM diperlukan adanya enterprise architecture. Dalam melakukan perancangan enterprise architecture pada penelitian ini menggunakan metode TOGAF ADM. Hasil dari perancangan enterprise architecture pada penelitian ini berupa enterprise architecture blueprint pada UMKM Penghasil Makanan Khas Daerah (company specific) dalam menunjang transformasi digital.
\end{abstract}

Kata kunci - Blueprint; Enterprise Architecture; TOGAF ADM; Transformasi Digital; UMKM.

\author{
Irfan Darmawan \\ Fakultas Rekayasa Industri, Jurusan Sistem Informasi \\ Universitas Telkom \\ Jalan Telekomunikasi No.1, Bandung \\ irfandarmawan@telkomuniversity.ac.id
}

\section{PENDAHULUAN}

Dewasa ini, perkembangan teknologi selalu mengalami perkembangan yang sangat pesat. Peningkatan penggunaan teknologi yang semakin mudah digunakan sehingga memiliki dampak secara langsung pada seluruh bidang kehidupan[1]. Adanya kemudahan dalam menggunakan teknologi dapat meningkatkan efektivitas dan efisiensi kerja suatu organisasi[2]. Dalam beberapa tahun terakhir, perusahaan-perusahaan hampir semua industri telah bertransformasi melakukan sejumlah inisiatif untuk memanfaatkan teknologi dan banyak mendapat keuntungan dari pemanfaatan tersebut. Adanya tranformasi digital yang berbasis sistem informasi, nilai bisnis diyakini akan semakin meningkat, oleh karna itu mutlak dibutuhkan pengembangan bisnis berbasis sistem informasi[3]. Transformasi digital sering melibatkan transformasi operasi bisnis utama dan mempengaruhi produk dan proses, serta struktur organisasi dan konsep manajemen [4]. Salah satu organisasi yang membutuhkan peran teknologi informasi untuk menuju transformasi digital adalah Usaha Mikro Kecil dan Menegah (UMKM) karena sebagian besar masih dikelola dengan metode konvensional dengan teknologi informasi belum optimal. Contoh dari pemanfaatan teknologi informasi untuk meningkatkan produktivitas bisnis UMKM adalah dengan menggunakan aplikasi dan website.

Namun demikian, bisnis UMKM tidak selalu berjalan mulus yang sejalan dengan penerapan transformasi digital. Masih banyaknya hambatan dan kendala baik yang bersifat internal maupun eksternal yang harus dihadapi para pelaku UMKM [5]. Contoh permasalahan klasik yang dihadapi [6] yaitu : rendahnya produktivitas. Beberapa kendala yang dialami oleh UMKM Penghasil Makanan Khas Daerah antara lain seperti keterbatasan mendapatkan pasokan bahan baku, banyaknya pesaing produk yang sama, catatan keuangan yang masih manual, belum adanya standarisasi produk, jangkauan pemasaran yang masih sempit, dan keterbatasan inovasi pengolahan kacang. Maka dari itu, perlunya pemanfaatan teknologi informasi yang selaras 
dengan kebutuhan bisnis. Untuk menyelaraskan antara bisnis dan teknologi UMKM maka diperlukan adanya enterprise architecture [7][8].

Salah satu best practice framework untuk mengembangkan EA dalam organisasi adalah TOGAF [9]. TOGAF memiliki sebuah metode dalam membuat, mengelola dan mengimplementasikan arsitektur enterprise dan sistem informasi pada organisasi yang disebut dengan Architecture Development Method (ADM). Abramowicz melakukan survey dalam penelitiannya yang berfokus pada pemanfaatan Enterprise Architecture Management (EAM) atau TOGAF pada UKM, menjelaskan bahwa arsitektur bisnis (Business Architecture) [12] merupakan hal yang paling penting dari seluruh fase ADM. Fase ini bertujuan untuk mendefinisikan tujuan bisnis yang menjadi fokus utama dari semua fase yang ada. Dan dari fase ADM pada TOGAF terfokus pada business architecture dengan poin sebesar $83 \%$ dan diikuti oleh architecuture vision dan information system architecture sebesar 70\% [5]. Selain itu, banyak faktor yang harus dipertimbangkan ketika ingin menyesuaikan TOGAF. Salah satunya adalah karakteristik dari UMKM ini[7][8]. Untuk perancangan enterprise architecture pada penelitian ini dimulai pada fase Preliminary sampai dengan fase Technology Architecture. Hasil dari perancangan enterprise architecture pada penelitian ini berupa enterprise architecture blueprint sebagai bentuk transformasi digital pada UMKM Penghasil Makanan Khas Daerah.

\section{METODE}

Metode yang digunakan dalam perancangan enterprise architecture ini adalah menggunakan metode yang ada pada framework TOGAF yang disebut TOGAF ADM. Namun sebelumnya, dilakukan klasifikasi UMKM berdasarkan karakteristiknya untuk mengetahui faktor-faktor apa saja yang harus dipertimbangkan ketika ingin melakukan perancangan enterprise architecture dengan framework TOGAF.

\subsection{Karakteristik UMKM}

Pada penelitian ini, menggunakan studi kasus UMKM Penghasil Makanan Khas daerah yang dikategorikan sebagai usaha kecil menurut karakteristik aset dan omset berdasarkan UU Nomor 20 Tahun 2008[11].

\subsection{TOGAF ADM}

TOGAF ADM merupakan metode generik yang berisikan sekumpulan aktivitas yang digunakan dalam memodelkan pengembangan arsitektur enterprise. Metode ini juga dibisa digunakan sebagai panduan atau alat untuk merencanakan, merancang, mengembangkan dan mengimplementasikan arsitektur sistem informasi untuk organisasi [10]. Dalam TOGAF juga memandang enterprise architecture ke dalam empat domain seperti bisnis, data, aplikasi dan teknologi. Pada TOGAF ADM terdiri dari 9 fase yang saling terhubung. Untuk perancangan enterprise architecture pada penelitian ini dimulai pada fase Preliminary, Architecture Vision (fase A), Business Architecture (fase B), Information System Architecture (fase C) dan Technology Architecture (fase D).

\section{HASIL DAN DISKUSI}

\subsection{Karakteristik UMKM}

Pada penelitian ini, menggunakan studi kasus UMKM Penghasil Makanan Khas daerah yaitu Kacang Bogares Rasmadi Putri yang dikategorikan sebagai usaha kecil menurut karakteristik aset dan omset berdasarkan UU Nomor 20 Tahun 2008[11]. Berikut pada TABEL 1 merupakan penjelasan detail terkait klasifikasi UMKM.

TABEL 1 Karakteristik UMKM

\begin{tabular}{|c|c|c|c|}
\hline \multirow{2}{*}{$\begin{array}{l}\text { Usaha } \\
\text { Kecil }\end{array}$} & \multicolumn{2}{|c|}{ Kriteria } & \multirow[t]{2}{*}{ Deskripsi } \\
\hline & Aset & Omset & \\
\hline $\begin{array}{l}\text { Kacang } \\
\text { Bogares } \\
\text { Rasmadi } \\
\text { Putri }\end{array}$ & $\begin{array}{l}>\text { Rp } 50 \\
\text { juta-Rp } \\
500 \text { juta } \\
\text { (dalam } \\
\text { satu } \\
\text { tahun). }\end{array}$ & $\begin{array}{l}>\mathrm{Rp} 300 \\
\text { juta- Rp } \\
2,5 \mathrm{M} \\
\text { (dalam } \\
\text { satu } \\
\text { tahun). }\end{array}$ & $\begin{array}{l}\text { Untuk aset, modal awal yang } \\
\text { dikeluarkan untuk usaha adalah } \\
\text { Rp } 60 \text { juta. } \\
\text { Sedangkan untuk omset, usaha } \\
\text { ini menghasilkan Rp } 20 \text { juta } \\
\text { dalam sebulan, namun dibulan } \\
\text { tertentu seperti bulan lebaran, } \\
\text { atau bulan liburan omset yang } \\
\text { didapatkan bisa berlipat ganda } \\
\text { daripada bulan biasa. }\end{array}$ \\
\hline
\end{tabular}

\subsection{Perancangan $E A$ dengan TOGAF ADM}

Selain itu, pada bab ini juga membahas tentang perancangan enterprise architecture pada UMKM Penghasil Makanan Khas Daerah menggunakan TOGAF ADM dari fase preliminary sampai dengan fase Technology Architecture.

1) Fase Preliminary

Pada fase ini dibuat sebuah artefak berupa principle catalog yang berisi prinsip-prinsip yang digunakan untuk pengembangan fase arsitektur bisnis, arsitektur data, arsitektur aplikasi dan arsitektur teknologi. Berikut merupakan principle catalog pada UMKM Makanan Khas Daerah.

\section{a. Arsitektur Bisnis}

TABEL 2 Prinsip Arsitektur Bisnis

\begin{tabular}{ll}
\hline \multicolumn{1}{c}{ Prinsip } & \multicolumn{2}{c}{ Deskripsi } \\
\hline $\begin{array}{l}\text { Bisnis yang } \\
\text { berkesinambungan }\end{array}$ & $\begin{array}{l}\text { Keberlangsungan kegiatan operasional bisnis pada } \\
\text { UMKM tetap berjalan walaupun terdapat } \\
\text { masalah/gangguan. }\end{array}$ \\
\hline $\begin{array}{l}\text { Penyempurnaan } \\
\text { produk }\end{array}$ & $\begin{array}{l}\text { Penyempurnaan produk terus dikembangkan agar } \\
\text { menambah minat produk yang ditawarkan kepada } \\
\text { konsumen yang sesuai dengan kebutuhan pasar. }\end{array}$ \\
\hline $\begin{array}{l}\text { Menjamin kualitas } \\
\text { produk }\end{array}$ & $\begin{array}{l}\text { Meningkatkan kualitas produk dengan } \\
\text { menggunakan bahan-bahan berkualitas dan diolah } \\
\text { sesuai dengan standar produksi. }\end{array}$ \\
\hline $\begin{array}{l}\text { Kesesuaian } \\
\text { terhadap regulasi } \\
\text { pemerintah }\end{array}$ & $\begin{array}{l}\text { Semua proses yang ada harus sesaui dengan } \\
\text { regulasi pemerintah terkait UMKM. }\end{array}$ \\
\hline
\end{tabular}




\section{b. Arsitektur Data}

TABEL 3 Prinsip Arsitektur Data

\begin{tabular}{ll}
\hline \multicolumn{1}{c}{ Prinsip } & \multicolumn{1}{c}{ Deskripsi } \\
\hline Data adalah aset & $\begin{array}{l}\text { Semua data terkait UMKM merupakan aset yang } \\
\text { memiliki nilai, sehingga harus dijaga dan } \\
\text { dikelola dengan baik. }\end{array}$ \\
\hline \multirow{2}{*}{ Data dapat diakses } & $\begin{array}{l}\text { Data harus dapat diakses dengan mudah oleh } \\
\text { pengguna yang sesuai dengan tingkat otoritasnya } \\
\text { agar mudah dikelola. }\end{array}$ \\
\hline Data yang akurat & $\begin{array}{l}\text { Data harus dapat dipertanggungjawabkan } \\
\text { keasliannya. }\end{array}$ \\
\hline Integrasi data & $\begin{array}{l}\text { Semua data terkait UMKM dapat terhubung } \\
\text { antar pengguna untuk menunjang bisnisnya dan } \\
\text { mengurangi adanya redudansi data. }\end{array}$ \\
\hline Keamanan data & $\begin{array}{l}\text { Semua data harus terlindungi secara aman agar } \\
\text { terhindar dari resiko serangan maupun } \\
\text { eksploitasi data oleh pengguna yang tidak sesuai } \\
\text { dengan otoritasnya. }\end{array}$ \\
\hline
\end{tabular}

\section{Arsitektur Aplikasi}

TABEL 4 Prinsip Arsitektur Aplikasi

\begin{tabular}{ll}
\hline \multicolumn{1}{c}{ Prinsip } & \multicolumn{1}{c}{ Deskripsi } \\
\hline Usability Aplikasi & $\begin{array}{l}\text { Aplikasi mudah digunakan oleh pengguna (user } \\
\text { friendly) dan memiliki fungsionalitas yang } \\
\text { tinggi. }\end{array}$ \\
\hline $\begin{array}{l}\text { Fleksibilitas } \\
\text { Aplikasi }\end{array}$ & $\begin{array}{l}\text { Aplikasi dapat berfungsi dengan baik sesuai } \\
\text { platformnya sehingga tidak perlu diadakan } \\
\text { perubahan secara terus-menerus. }\end{array}$ \\
\hline
\end{tabular}

\section{d. Arsitektur Teknologi}

TABEL 5 Prinsip Arsitektur Teknologi

\begin{tabular}{ll}
\hline \multicolumn{1}{c}{ Prinsip } & \multicolumn{1}{c}{ Deskripsi } \\
\hline $\begin{array}{l}\text { Keamanan } \\
\text { Teknologi }\end{array}$ & $\begin{array}{l}\text { Teknologi harus terlindungi dari resiko yang } \\
\text { dapat terjadi baik internal maupun eksternal. }\end{array}$ \\
\hline Interoperabilitas & $\begin{array}{l}\text { Kemampuan teknologi dalam mendukung } \\
\text { pertukaran data. }\end{array}$ \\
\hline $\begin{array}{l}\text { Perubahan } \\
\text { teknologi sesuai } \\
\text { dengan kebutuhan } \\
\text { bisnis }\end{array}$ & $\begin{array}{l}\text { Perubahan teknologi harus disesuaikan dengan } \\
\text { kebutuhan yang ada sehingga dapat mendukung } \\
\text { operasional perusahaan secara maksimal. }\end{array}$ \\
\hline
\end{tabular}

\section{2) Fase A : Architecture Vision}

Architecture Vision merupakan fase pertama pada siklus TOGAF ADM. Dalam fase ini menjelaskan tentang nilai bisnis yang dimiliki oleh manajemen level atas (Top Level Management) pada UMKM yang akan digunakan untuk menentukan bagaimana rancangan EA yang diusulkan. Di bawah ini pada GAMBAR 1 merupakan gambar artefak yang ada pada Architecture Vision.

Solution Concept Diagram merupakan diagram penggambaran solusi teknologi informasi usulan yang dijadikan acuan dalam melakukan rancangan enterprise architecture. Pemetaan Solution Concept Diagram terdapat 3 kategori, yaitu Front Office, Middle Office, dan Back Office.

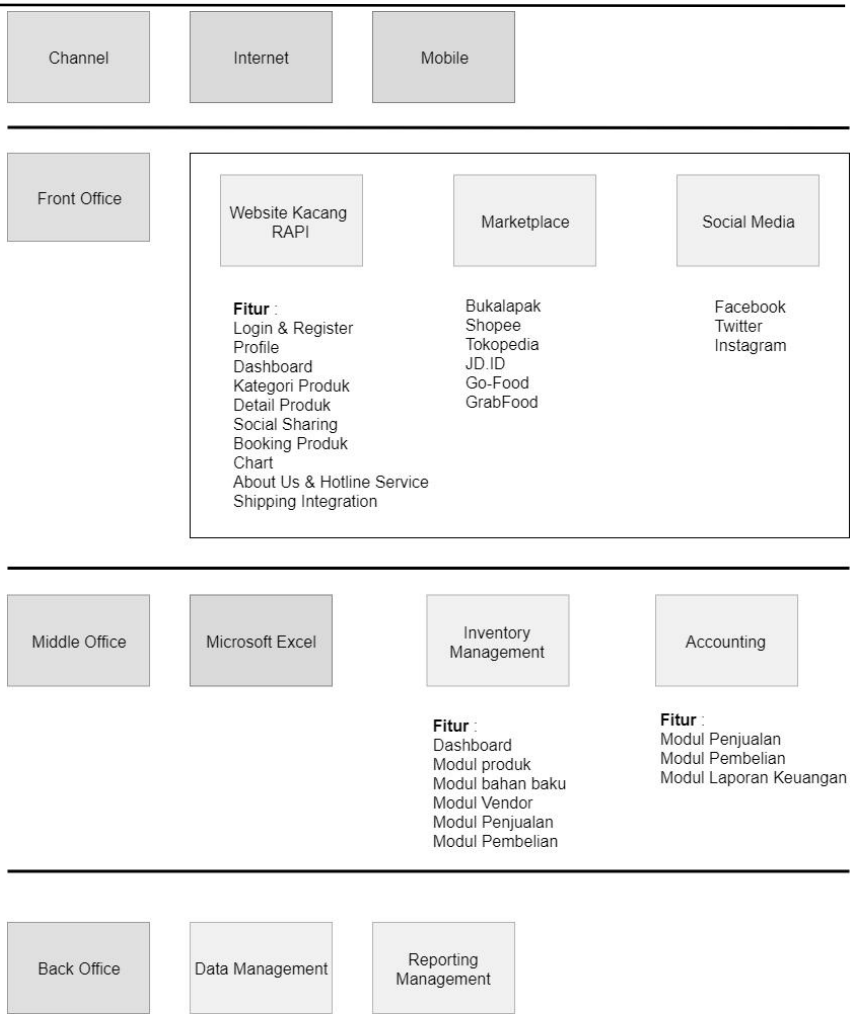

GAMBAR 1 Solution Concept Diagram

3) Fase B : Business Architecture

Pada fase ini digambarkan proses bisnis eksisting yang ada pada UMKM sehingga kemudian dibuatlah proses bisnis arsitektur target yang ingin dicapai. Pada TABEL 6 ini merupakan artefak katalog yang menjelaskan bagaimana keterkaitan antara driver, goal, objective pada UMKM.

TABEL 6 Driver, Goal, Objective Catalog

\begin{tabular}{|c|c|c|}
\hline Driver & Goal & Objective \\
\hline \multirow{3}{*}{$\begin{array}{l}\text { Peningkatan } \\
\text { efektivitas dan } \\
\text { efisiensi penggunaan } \\
\text { bahan baku }\end{array}$} & \multirow{2}{*}{$\begin{array}{l}\text { Mampu memenuhi } \\
\text { bahan baku kacang } \\
\text { secara konsisten }\end{array}$} & $\begin{array}{l}\text { Menjaga } \\
\text { bahan baku }\end{array}$ \\
\hline & & $\begin{array}{l}\text { Pemilihan vendor yang } \\
\text { konsisten dan stabil }\end{array}$ \\
\hline & $\begin{array}{l}\text { Meningkatkan } \\
\text { pengelolaan } \\
\text { control } \\
\text { produk }\end{array}$ & $\begin{array}{l}\text { Perlu adanya teknologi } \\
\text { produksi terbaru dan } \\
\text { cara menjalankan } \\
\text { quality control } \\
\text { terhadap produk }\end{array}$ \\
\hline \multirow{3}{*}{$\begin{array}{l}\text { Memberikan } \\
\text { pendapatan lebih bagi } \\
\text { UMKM }\end{array}$} & $\begin{array}{l}\text { Pencatatan keuangan } \\
\text { yang terstruktur }\end{array}$ & $\begin{array}{l}\text { Aplikasi keuangan } \\
\text { (Accounting) dalam } \\
\text { proses pencatatan } \\
\text { keuangan UMKM }\end{array}$ \\
\hline & $\begin{array}{l}\text { Mampu mengadakan } \\
\text { standarisasi produk }\end{array}$ & $\begin{array}{l}\text { Standarisasi produk } \\
\text { terpenuhi }\end{array}$ \\
\hline & $\begin{array}{l}\text { Meluasnya jangkauan } \\
\text { pemasaran }\end{array}$ & $\begin{array}{l}\text { Optimalisasi } \\
\text { penjualan }\end{array}$ \\
\hline \multirow{2}{*}{\begin{tabular}{l}
\multicolumn{2}{l}{ Meningkatkan } \\
kualitas produk agar \\
mampu bersaing \\
dengan \\
makanan khas daerah \\
lainnya di pasar \\
Indonesia
\end{tabular}} & \multirow{2}{*}{$\begin{array}{l}\text { Mampu } \text { bersaing } \\
\text { dengan produk yang } \\
\text { sama }\end{array}$} & $\begin{array}{l}\text { Meningkatkan } \\
\text { pengelolaan jumlah } \\
\text { stok produk di gudang }\end{array}$ \\
\hline & & $\begin{array}{l}\text { Adanya data penjualan } \\
\text { berdasarkan kategori } \\
\text { produk }\end{array}$ \\
\hline
\end{tabular}


Selain itu, artefak lain yaitu Business Service / Functional / Process Catalog pada TABEL 7 merupakan katalog yang mendeskripsikan fungsi bisnis (business function), layanan bisnis (business service), dan proses bisnis (business process) yang ada pada UMKM Makanan Khas Daerah.

TABEL 7 Business Service / Functional / Process Catalog

\begin{tabular}{|c|c|c|}
\hline $\begin{array}{l}\text { Business } \\
\text { Function }\end{array}$ & Business Service & Business Process \\
\hline \multirow{3}{*}{ Produksi } & \multirow{2}{*}{ Pembuatan produk } & $\begin{array}{l}\text { Persiapan pembuatan } \\
\text { kacang }\end{array}$ \\
\hline & & Pembuatan kacang \\
\hline & Packaging produk & Packaging kacang \\
\hline \multirow{4}{*}{ Pengadaan } & Pengelolaan gudang & Pengelolaan bahan baku \\
\hline & Pembelian barang & Pembelian bahan baku \\
\hline & \multirow[b]{2}{*}{ Pengelolaan vendor } & Seleksi vendor \\
\hline & & $\begin{array}{l}\text { Penilaian vendor } \\
\text { (Kategorisasi vendor) }\end{array}$ \\
\hline \multirow{4}{*}{ Keuangan } & \multirow{4}{*}{ Pengelolaan keuangan } & $\begin{array}{l}\text { Pencatatan penjualan via } \\
\text { offline }\end{array}$ \\
\hline & & $\begin{array}{l}\text { Pencatatan penjualan via } \\
\text { marketplace }\end{array}$ \\
\hline & & $\begin{array}{l}\text { Pencatatan penjualan via } \\
\text { website }\end{array}$ \\
\hline & & $\begin{array}{l}\text { Pencatatan Laporan akhir } \\
\text { UMKM }\end{array}$ \\
\hline Pemasaran & Kategorisasi konsumen & Pemberian diskon \\
\hline \multirow{4}{*}{ Distribusi } & \multirow{4}{*}{$\begin{array}{l}\text { Pengelolaan penyebaran } \\
\text { produk }\end{array}$} & Penjualan ke offline \\
\hline & & $\begin{array}{l}\text { Penjualan ke supermarket } \\
\text { / Distributor }\end{array}$ \\
\hline & & Penjualan ke marketplace \\
\hline & & Penjualan ke wesbite \\
\hline
\end{tabular}

Ket.

Improvement Business Process

: Target Business Process

Selain itu terdapat artefak Role Catalog merupakan artefak yang menjelaskan jobdesk atau tugas dari setiap stakeholder dalam menjalankan kegiatan proses bisnisnya pada UMKM. Pada TABEL 8 di bawah ini merupakan role catalog yang terdapat pada UMKM Penghasil Makanan Khas Daerah.

TABEL 8 Role Catalog

\begin{tabular}{|c|c|c|}
\hline No & Stakeholder & Activity \\
\hline 1 & Owner & $\begin{array}{l}\text { Bertanggung jawab atas koordinasi, evaluasi, } \\
\text { analisis pelaksanaan seluruh operasional proses } \\
\text { bisnis yang ada pada UMKM apakah sesuai dengan } \\
\text { visi, misi, dan tujuan UMKM. }\end{array}$ \\
\hline 2 & $\begin{array}{l}\text { Bagian } \\
\text { Produksi }\end{array}$ & $\begin{array}{l}\text { Mengelola proses untuk menghasilkan produk dari } \\
\text { UMKM sehingga dapat mendapatkan profit. }\end{array}$ \\
\hline 3 & $\begin{array}{l}\text { Bagian } \\
\text { Pemasaran }\end{array}$ & $\begin{array}{l}\text { Mengelola proses bisnis untuk memasarkan produk } \\
\text { dari UMKM agar diketahui oleh masyarakat. }\end{array}$ \\
\hline 4 & $\begin{array}{l}\text { Bagian } \\
\text { Distribusi }\end{array}$ & $\begin{array}{l}\text { Mengelola proses bisnis untuk mendistribusikan } \\
\text { atau menyebarkan produk dari UMKM kepada } \\
\text { masyarakat untuk dikonsumsi. }\end{array}$ \\
\hline 5 & $\begin{array}{l}\text { Bagian } \\
\text { Pengadaan }\end{array}$ & $\begin{array}{l}\text { Mengelola proses bisnis untuk mengadakan atau } \\
\text { pengadaan bahan-bahan dari vendor yang } \\
\text { dibutuhkan dalam proses produksi. }\end{array}$ \\
\hline 6 & $\begin{array}{l}\text { Bagian } \\
\text { Keuangan }\end{array}$ & $\begin{array}{l}\text { Mengelola proses bisnis untuk proses pencatatan } \\
\text { keuangan dari UMKM. }\end{array}$ \\
\hline
\end{tabular}

4) Fase C : Information System Architecture

Information System Architecture adalah fase ke tiga dari TOGAF ADM. Fase ini menjelaskan bagaimana arsitektur sistem informasi dikembangkan yang mencakup Data Architecture dan Application Architecture yang akan digunakan oleh UMKM.

a. Fase Data Architecture

Pada fase Arsitektur Data, diidentifikasikan datadata yang digunakan saat ini dan data-data yang dibutuhkan pada masa mendatang. Berikut merupakan artefak Application / Data Matrix yang menjelaskan kaitan entitas dengan aplikasi yang ada pada UMKM.

Aplikasi Pengelolaan Keuangan

TABEL 9 Application/Data Matrix Pengelolaan Keuangan

\begin{tabular}{|c|c|c|}
\hline Deskripsi & Entitas Data & Tipe Data \\
\hline \multirow{9}{*}{$\begin{array}{l}\text { Aplikasi } \\
\text { pengelola } \\
\text { penjualan } \\
\text { keuangan. }\end{array}$} & $\mathrm{PO}$ & Transactional data \\
\hline & Invoice & Transactional data \\
\hline & Konsumen & Master data \\
\hline & Pegawai & Master data \\
\hline & Penjualan & Transactional data \\
\hline & Diskon & Transactional data \\
\hline & Laporan & Transactional data \\
\hline & Faktur & Transactional data \\
\hline & $\begin{array}{l}\text { User } \\
\text { management }\end{array}$ & Master data \\
\hline
\end{tabular}

Aplikasi Pengelolaan Pergudangan

TABEL 10 Application/Data Matrix Pengelolaan Pergudangan

\begin{tabular}{lll}
\hline \multicolumn{1}{c}{ Deskripsi } & \multicolumn{1}{c}{ Entitas Data } & \multicolumn{1}{c}{ Tipe Data } \\
\hline & Produk & Master data \\
\cline { 2 - 3 } & Bahan Baku & Master data \\
\cline { 2 - 3 } & Alat & Master data \\
\cline { 2 - 3 } A & Transactional data \\
\cline { 2 - 3 } $\begin{array}{l}\text { Anvoice } \\
\text { pengelola } \\
\text { pergudangan } \\
\text { dan vendor }\end{array}$ & Vendor & Master data \\
\cline { 2 - 3 } & Pegawai & Master data \\
\cline { 2 - 3 } & Konsumen & Master data \\
& Detail produk & Transactional data \\
& Faktur & Transactional data \\
& Penjualan & Transactional data \\
& User & Master data \\
& Management & Transactional data \\
\hline
\end{tabular}

Website

TABEL 11 Application/Data Matrix Website

\begin{tabular}{|c|c|c|}
\hline Deskripsi & Entitas Data & Tipe Data \\
\hline \multirow{10}{*}{$\begin{array}{l}\text { Digunakan } \\
\text { sebagai media } \\
\text { penjualan dan } \\
\text { pemasaran } \\
\text { produk UMKM. }\end{array}$} & Produk & Master data \\
\hline & Konsumen & Master data \\
\hline & Penjualan & Transactional data \\
\hline & Ekspedisi & Master data \\
\hline & Detail produk & Transactional data \\
\hline & Faktur & Transactional data \\
\hline & Diskon & Transactional data \\
\hline & Pegawai & Master data \\
\hline & PO & Transactional data \\
\hline & Invoice & Transactional data \\
\hline
\end{tabular}

Ket.

: Target Data Entity 


\section{b. Fase Application Architecture}

Pada fase Arsitektur Aplikasi menjelaskan aplikasi-aplikasi yang digunakan saat ini dan aplikasiaplikasi yang dibutuhkan pada masa mendatang di UMKM. Pada UMKM Makanan Khas Daerah, dibuat target aplikasi yaitu Aplikasi Pengelolaan Pergudangan, Aplikasi Pengelolaan Kuangan dan Website UMKM. Ketiga aplikasi tersebut saling terintegrasi satu sama lain. GAMBAR 2 di bawah ini merupakan kaitan antar aplikasi yang ada pada UMKM.

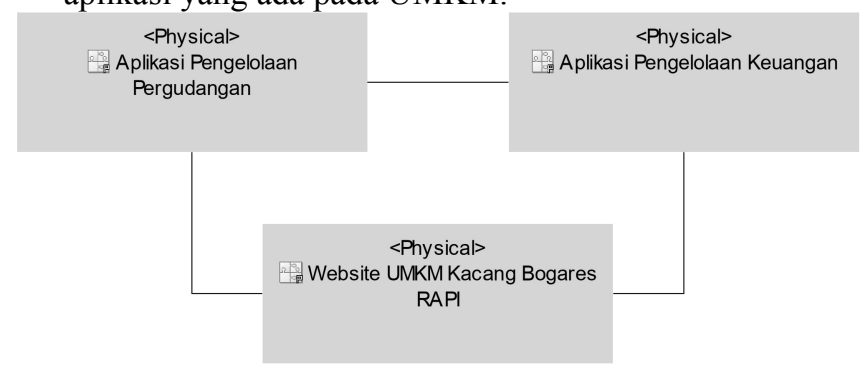

GAMBAR 2 Application Communication Diagram

Selain itu, terdapat artefak Application / Role Matrix yang menggambarkan hubungan antara application component dengan proses bisnis yang ada pada UMKM (TABEL 12)

TABEL 12 Application / Role Matrix

\begin{tabular}{lccc}
\hline \multicolumn{1}{c}{ Proses Bisnis } & \multicolumn{3}{c}{ Aplikasi } \\
\cline { 2 - 4 } & $\begin{array}{c}\text { Pengelolaan } \\
\text { Pergudangan }\end{array}$ & $\begin{array}{c}\text { Pengelolaan } \\
\text { Keuangan }\end{array}$ & Website \\
\hline Persiapan pembuatan kacang & $\mathrm{V}$ & - & - \\
\hline Pembuatan kacang & $\mathrm{V}$ & - & - \\
\hline Packaging kacang & $\mathrm{V}$ & - & $\mathrm{V}$ \\
\hline Pengelolaan bahan baku & $\mathrm{V}$ & - & - \\
\hline Pembelian bahan baku & $\mathrm{V}$ & $\mathrm{V}$ & - \\
\hline Seleksi vendor & $\mathrm{V}$ & - & - \\
\hline $\begin{array}{l}\text { Penilaian vendor } \\
\text { (Kategorisasi vendor) }\end{array}$ & $\mathrm{V}$ & - & - \\
\hline $\begin{array}{l}\text { Pencatatan penjualan via } \\
\text { offline }\end{array}$ & - & $\mathrm{V}$ & - \\
\hline $\begin{array}{l}\text { Pencatatan penjualan via } \\
\text { marketplace }\end{array}$ & - & $\mathrm{V}$ & - \\
\hline $\begin{array}{l}\text { Pencatatan penjualan via } \\
\text { website }\end{array}$ & - & $\mathrm{V}$ & $\mathrm{V}$ \\
\hline $\begin{array}{l}\text { Pencatatan Laporan akhir } \\
\text { UMKM }\end{array}$ & - & $\mathrm{V}$ & $\mathrm{V}$ \\
\hline Pemberian diskon & - & $\mathrm{V}$ & $\mathrm{V}$ \\
\hline Penjualan ke offline & $\mathrm{V}$ & $\mathrm{V}$ & - \\
\hline $\begin{array}{l}\text { Penjualan ke supermarket / } \\
\text { Distributor }\end{array}$ & $\mathrm{V}$ & $\mathrm{V}$ & - \\
\hline Penjualan ke marketplace & $\mathrm{V}$ & $\mathrm{V}$ & - \\
\hline Penjualan ke wesbite & $\mathrm{V}$ & $\mathrm{V}$ & $\mathrm{V}$ \\
\hline
\end{tabular}

\section{5) Fase D : Technology Architecture}

Pada Fase Arsitektur Teknologi dihasilkan artefak Technology Portfolio Catalog (TABEL 13) yang dibuat dengan tujuan untuk mengidentifikasikan serta mengelola keseluruhan teknologi yang ada seperti perangkat keras, perangkat lunak infrastruktur, dan perangkat lunak aplikasi.
TABEL 13 Technology Portfolio Catalog

\begin{tabular}{|c|c|c|c|}
\hline Type & $\begin{array}{l}\text { Product } \\
\text { Name }\end{array}$ & Vendor & Description \\
\hline PC / Laptop & $\begin{array}{l}\text { Aplikasi } \\
\text { Klien }\end{array}$ & - & $\begin{array}{l}\text { Digunakan oleh karyawan } \\
\text { untuk membantu proses } \\
\text { bisnis pada UMKM. }\end{array}$ \\
\hline Printer & $\begin{array}{l}\text { Canon } \\
\text { PIXMA } \\
\text { TR4570S }\end{array}$ & Canon & $\begin{array}{l}\text { Digunakan sebagai media } \\
\text { pencetak, scan, copy } \\
\text { dokumen. }\end{array}$ \\
\hline Router & ISP Router & TP Link & $\begin{array}{l}\text { Digunakan sebagai alat } \\
\text { koneksi antara pengguna } \\
\text { dengan provider ISP. }\end{array}$ \\
\hline \multirow{4}{*}{$\begin{array}{l}\text { Application } \\
\text { Server }\end{array}$} & $\begin{array}{l}\text { Server } \\
\text { (Intel } \mathbb{} \\
\text { Core }^{\mathrm{TM}} \text { i3 } \\
\text { generasi ke-2 } \\
3,1 \mathrm{GHz} \text { ) }\end{array}$ & Dell & $\begin{array}{l}\text { Digunakan sebagai } \\
\text { penyedia layanan yang } \\
\text { terhubung pada PC Client. }\end{array}$ \\
\hline & $\begin{array}{l}\text { OS Server } \\
\text { (Windows } \\
\text { Server) }\end{array}$ & Microsoft & $\begin{array}{lr}\text { Sistem operasi yang } \\
\text { digunakan } \\
\text { menjalankan perangkat } \\
\text { lunak pada sebuah server. }\end{array}$ \\
\hline & $\begin{array}{l}\text { Database } \\
\text { Server } \\
\text { (MySQL) }\end{array}$ & Oracle & $\begin{array}{l}\text { Server yang digunakan } \\
\text { untuk penyedia database } \\
\text { yang diintegrasikan } \\
\text { dengan aplikasi. }\end{array}$ \\
\hline & $\begin{array}{l}\text { Web Server } \\
\text { (Apache) }\end{array}$ & Oracle & $\begin{array}{l}\text { Server yang digunakan } \\
\text { untuk meletakkan aplikasi } \\
\text { berbasis website. }\end{array}$ \\
\hline Mail Server & Gmail & Google & $\begin{array}{l}\begin{array}{l}\text { Digunakan untuk fungsi } \\
\text { email/surat }\end{array} \\
\text { internal/eksternal. }\end{array}$ \\
\hline \multirow{6}{*}{$\begin{array}{l}\text { Website } \\
\text { Server }\end{array}$} & $\begin{array}{l}\text { VPS (vCPU } \\
2.0 \mathrm{GHz} 4.0)\end{array}$ & IdCloudhost & $\begin{array}{l}\text { Layanan hosting yang } \\
\text { paling banyak digunakan } \\
\text { untuk mengonlinekan } \\
\text { website. }\end{array}$ \\
\hline & $\begin{array}{l}\text { OS Server } \\
\text { (Linux } 16.04 \\
\text { LTS) }\end{array}$ & Linux & $\begin{array}{lr}\text { Sistem operasi yang } \\
\text { digunakan } \\
\text { menjalankan perangkat } \\
\text { lunak pada sebuah server. }\end{array}$ \\
\hline & $\begin{array}{l}\text { Database } \\
\text { Server } \\
(M y S Q L)\end{array}$ & Oracle & $\begin{array}{l}\text { Server yang digunakan } \\
\text { untuk penyedia database } \\
\text { yang diintegrasikan } \\
\text { dengan aplikasi. }\end{array}$ \\
\hline & $\begin{array}{l}\text { Web Server } \\
\text { (Nginx) }\end{array}$ & Igor Sysoev & $\begin{array}{l}\text { Server yang digunakan } \\
\text { untuk meletakkan aplikasi } \\
\text { berbasis website. }\end{array}$ \\
\hline & $\begin{array}{l}\text { Programming } \\
\text { language } \\
(P H P)\end{array}$ & $\begin{array}{l}\text { PHP Dev. } \\
\text { Team }\end{array}$ & $\begin{array}{lr}\begin{array}{l}\text { Aturan/sintaks } \\
\text { digunakan }\end{array} & \text { yang } \\
\text { mendefinisikan } & \text { program } \\
\text { komputer. } & \\
\end{array}$ \\
\hline & Domain & IdCloudhost & $\begin{array}{lr}\text { Nama unik yang } \\
\text { digunakan } \\
\text { mengidentifikasikan } \\
\text { alamat IP. }\end{array}$ \\
\hline
\end{tabular}

\subsection{Hasil Blueprint EA Company Specific}

Setelah melakukan perancangan, dibuatlah sebuah blueprint yang menggambarkan rancangan EA secara keseluruhan untuk UMKM Makanan Khas Daerah dengan karakteristik usaha kecil seperti pada GAMBAR 3-5 di bawah ini. Blueprint ini dapat digunakan sebagai referensi perancangan enterprise architecture untuk UMKM sejenis makanan khas daerah lainnya. Penggunaan blueprint ini disesuaikan dengan kondisi dan karateristik UMKM tersebut. 


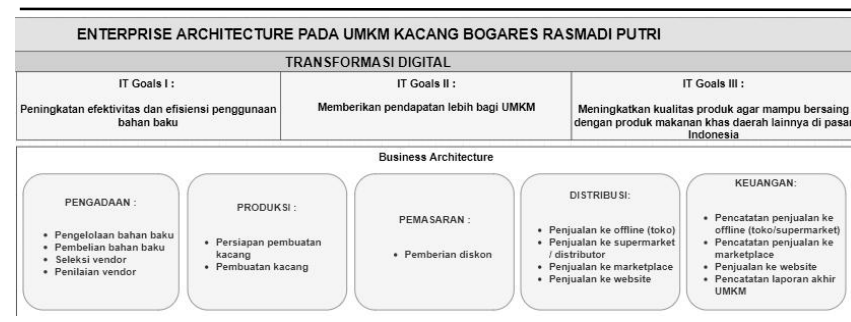

GAMBAR 3 EA Blueprint (IT Goals dan Business Architecture)

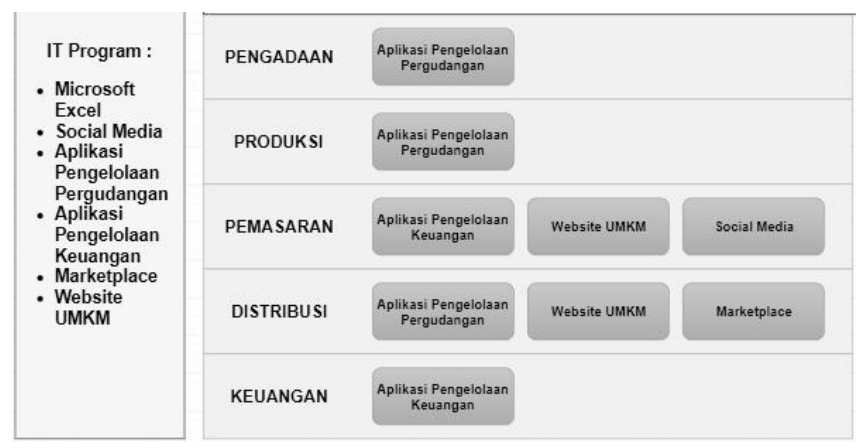

GAMBAR 4 EA Blueprint (Pemetaan IT Program)

\begin{tabular}{|c|}
\hline Technology Architecture : \\
- Penambahan Internet \\
- Penambahan Server PC \\
Penambahan Router \\
\hline Application Architecture : \\
- Aplikasi Pengelolaan Pergudangan \\
- Aplikasi Pengelolaan Keuangan \\
- Marketplace \\
\hline \multicolumn{1}{c|}{ Data Entity : } \\
Produk, bahan baku, alat, PO, invoice, faktur, vendor, \\
konsumen, pegawai, penjualan, detail produk, user \\
management, laporan, diskon, ekspedisi
\end{tabular}

GAMBAR 5 EA Blueprint ( IS Architecture dan Technology Architecture)

\section{KESIMPULAN}

Berdasarkan hasil penelitian yang telah dilakukan, maka dapat disimpulkan bahwa perancangan enteprise architecture blueprint untuk UMKM Penghasil Makanan Khas Daerah antara lain seperti perbaikan dan penambahan proses bisnis pada fungsi pengadaan, produksi, pemasaran, distribusi dan keuangan dalam mendukung goals antara lain seperti peningkatan efektifitas dan efisiensi bahan baku, memberikan keuntungan lebih bagi UMKM, dan meningkatkan kualitas produk agar mampu bersaing dengan produk makanan khas daerah lainnya di pasar Indonesia. Selain itu, adanya pembuatan database seperti database konsumen, vendor, produk, bahan baku, alat dan lain-lain disesuaikan dengan kebutuhan UMKM. Diusulkan juga adanya pemanfaatan penggunaan aplikasi pengelolaan pergudangan untuk mengelola bahan baku, produk, vendor, penjualan; aplikasi pengelolaan keuangan untuk mengelola keuangan UMKM; website sebagai media pemasaran dan penjualan; marketplace sebagai media penjualan dan teknologi target untuk mendukung transformasi digital pada UMKM Penghasil Makanan Khas Daerah. Blueprint ini dapat digunakan oleh UMKM yang sejenis dengan Makanan Khas Daerah yang bertipe usaha kecil.

\section{DAFTAR PUSTAKA}

[1] F. M. Cesaroni and D. Consoli, "Are Small Businesses Really Able to Take Advantage of Social Media?: Discovery Service para Universidad Del Pacifico," Electron. J. Knowl. Manag., vol. 13, no. 4, pp. 257-268, 2015.

[2] N. Venkatraman and J. C. Henderson, "Strategic alignment: leveraging information technology for transforming organizations," IBM Syst. J., vol. 32, no. 1, pp. 472-484, 1993.

[3] Y.-Y. K. C. Y.-L. J. Yu-Hsien Wu, "Effect of Digital Transformation on Organisational Performance of SMEs: Evidence from the Taiwanese Textile Industry's Web Portal," Emerald Insight, vol. 26, no. 1, p. , 2018.

[4] C. Matt, T. Hess, and A. Benlian, "Digital Transformation Strategies," Bus. Inf. Syst. Eng., vol. 57, no. 5, pp. 339-343, 2015.

[5] D. Goerzig and T. Bauernhansl, "Enterprise Architectures for the Digital Transformation in Small and Medium-sized Enterprises," Procedia CIRP, vol. 67, pp. 540-545, 2018.

[6] J. Jauhari, “Upaya Pengembangan Usaha Kecil Dan Menengah (Ukm) Dengan Memanfaatkan ECommerce," J. Sist. Inf., vol. 2, no. 1, pp. 159-168, 2014.

[7] Dwipriyoko, E. Literature Review on New Generation Cooperative Enterprise Architecture. JURNAL TIARSIE, Vol.14, 51-56, 2017

[8] Dwipriyoko, E. Perancangan Arsitektur Aplikasi Open Source untuk Koperasi Generasi Baru, Studi Kasus Koperasi Terbaik Malaysia. SNIA 2017 UNJANI, Computer Crime and Digital Evidence, 3, 145-150, 2017

[9] E. B. Setiawan, "Pemilihan EA Framework," Semin. Nas. Apl. Teknol. Inf., vol. 2009, no. SNATI, pp. 114-119, 2009.

[10] R. Weisman, An Overview of TOGAF. Ontario, Canada: The Open Group, 2011.

[11] L. P. P. Indonesia, PROFIL BISNIS USAHA MIKRO, KECIL DAN MENENGAH (UMKM). Jakarta: Bank Indonesia, 2014

[12] Dwipriyoko, E. New Generation Cooperative Financial Mathematical Model Preliminary Concept. Journal of Engineering and Applied Sciences, Vol.12, No.18, 4590-4594, 2017 